\title{
EL PROYECTO EDUCATIVO DE JOSÉ MARTÍ: UNA LECTURA DESDE LA PEDAGOGÍA CRÍTICA
}

\author{
Jacqueline García Fallas
}

Recibido 11-XI-2003

- Aceptado 11-XI-2003

\begin{abstract}
Resumen: En este artículo se presenta un análisis crítico de la propuesta educativa del escritor, filósofo y abogado cubano del siglo XIX, José Martí. Se realiza un recorrido por los principales conceptos de su planteamiento de la educación como un proyecto político nacional, en él se destacan las relaciones entre la educación y la sociedad, la crítica al modelo educativo tradicional y la visión prospectiva del sujeto educativo, así como el papel de transformación social implícito en la educación latinoamericana.
\end{abstract}

Palabras clave: Filosofía de la Educación, Pensamiento Latinoamericano, Pedagogía Crítica, Educación y Sociedad.

\section{Introducción}

Las primeras frases del pensamiento filosófico de la educación de José Martí promueven mi interés por incursionar en ese pensamiento a partir de la revisión de textos en su mayoría periodísticos, que caracterizan su visión de un proyecto educativo nacional:

La educación es como un árbol: se siembra una semilla y se abre en muchas ramas. Sea la gratitud del pueblo que se educa el árbol protector, en las tempestades y las lluvias, de los hombres que hoy les hacen tanto bien. Hombres recogerá quien siembre escuelas.” Martí, J. (1878) De Guatemala, México, Edición de El siglo XXI. En José Martí, Obras Completas, Tomo 7, p. 157.

En una primera lectura de los textos se muestra con claridad la preocupación liberal por transformar la sociedad, afín al movimiento sociocultural e histórico de su época. En otra aproximación a su ideario filosófico de la educación aparece una vertiente importante de análisis que renueva la vigencia del pensamiento martiano en la comprensión de la educación en el seno de la sociedad.

Esa vertiente de análisis es la denominada pedagogía crítica, un enfoque teórico de la educación que ofrece una lectura política del proceso educativo como clave para la transformación social. Se percibe la educación como un espacio sociocultural 
liberador de las personas; una libertad obtenida a través de las condiciones políticas facilitadas en la sociedad o construidas por la apertura de un campo distinto de necesidades socioculturales y el fortalecimiento de una visión crítica de los acontecimientos históricos.

Desde la libertad se puede tejer la transformación social, la cual requiere a un ser humano vinculado con su realidad, activo en las decisiones y comprometido con un proyecto social que no sólo tiene un alcance local, sino también regional o mundial. Esta posición se percibe en las ideas de Martí en torno a la importancia de la educación, visualiza la historia de cada país como parte de un engranaje común que requiere ser pensado como una totalidad, no homogénea, pero integradora de esa realidad sociocultural compartida, que se podría llamar a América.

La concreción de ese proyecto social se realiza a través de la educación, percibida como el escenario de una revolución que genere una nueva sociedad e historia. Martí no sólo piensa en los niveles educativos de preescolar, primaria, secundaria, técnica y universitaria como espacios formales del proceso educativo, sino también asigna un lugar importante a la educación no formal e informal. Sin embargo, la transformación social exige una revisión y un cambio en la perspectiva de los lazos del proceso educativo con la sociedad, el sujeto, la formación docente y el curriculum.

Lo anterior permite que tome la decisión de pensar en forma global, las características conceptuales del proceso educativo descrito por Martí a partir de la pedagogía crítica. Este proyecto propone los siguientes principios teóricos de índole filosófica que se vierten en su visión de la razón de ser de la educación en una sociedad:

La formación cultural como acto liberador.

El carácter axiológico de la educación.

El carácter patriótico de la educación.

El carácter popular de la educación.

El carácter democrático de la educación.

El carácter científico de la educación.
La educación como derecho y deber de todos los ciudadanos.

La educación como tarea de masas.

La unidad de la función instructiva y educativa en el acto docente.

La combinación de la enseñanza teórica con la práctica.

La incorporación de la educación física a la formación del escolar.

La combinación del estudio y el trabajo en las escuelas.

La vinculación de la escuela con la comunidad.

La educación laica.

La coeducación. (Pérez, F:2003:9).

Estos principios se analizan alrededor de los siguientes temas:

1 Educación y sociedad.

1 Percepción de la dinámica social.

$1 \quad$ Educación para todos.

1 Educación y equidad de oportunidades.

$1 \quad$ Educación y cambio social.

$1 \quad$ La transformación social: una exigencia latinoamericana de la educación.

$1 \quad$ Crítica al modelo educativo tradicionalista.

$1 \quad$ Sujeto del proceso educativo.

El proyecto educativo como depositario de principios filosóficos que se concretan en el curriculum escolar, se comprende a partir de la siguiente visión de la educación, la cual se apoya en la pedagogía crítica, según la cual la educación se concibe:

a) Como una actividad que se expresa de formas distintas, que despierta procesos que tienen ciertas consecuencias en los alumnos, por lo que es preciso entender los diversos métodos de conducirla.

b) Como el contenido de un proyecto de socialización y de formación en términos de lo que se transmite, lo que se pretende, los efectos que se logran.

c) Como los agentes y elementos que determinan la actividad y el contenido 
en los procesos de aprendizaje: Fuerzas sociales, institución escolar, ambiente y clima pedagógico, profesores, materiales, entre otros. (Gimeno, J \& Pérez, A: 2000).

\section{Educación y sociedad}

La educación tiene una vital importancia para la sociedad, no sólo tiene una función reproductora de las creencias, valores, conocimientos y consciencias que fundamentan el quehacer cotidiano de los actores sociales, sino también su transformación. El encuentro dialéctico de estas dos fuerzas (reproducción-transformación), hace de la educación un fenómeno social en permanente crisis. Esta crisis se plasma en los procesos de socialización que se gestan en los espacios educativos.

Parafraseando a Gimeno (2001:122) la sociedad constituye redes de intercambio sociocultural generadas por los vínculos afectivos y cognitivos que se deben afianzar o corregir. El sujeto puede tener cierto autocontrol en esas redes, pero nunca tiene asegurado su dominio, en lo que a él le afecta y en los efectos que él tiene sobre los demás. Para que sea posible la convivencia ordenada en sociedad refleja un entretejido de redes que confluyen en un cierto orden en el juego de las relaciones sociales para garantizar la "seguridad" de cada individuo y la del conjunto. Lo anterior posibilita establecer un espacio público a través de las instituciones, reglas y leyes sociales, las cuales, en última instancia, son creaciones culturales.

\section{Percepción de la dinámica social}

La educación requiere ser visionaria sobre el desarrollo social. Para ello es importante que el ser humano viva conforme a su época y a los cambios que gesta. Además es relevante que ésta vaya más allá de los enfoques conceptuales que estén en boga en los momentos específicos de cada contexto histórico. Puede partir de éstos para reflexionar sobre el porvenir, anticipando situaciones a las que las personas son sometidas por el cambio social. Esta posición martiana se expresa en el siguiente texto en el que sobre la disputa de la conveniencia o no del latín y el griego en el curriculum universitario, permite entrever el compromiso de la educación para hacerle frente a las exigencias sociales gestadas por la heterogeneidad de los actores sociales:

La educación tiene un deber ineludible para con el hombre, -no cumplirlo es un crimen: conformarle a su tiempo- sin desviarle de la grandiosa y final tendencia humana. Que el hombre viva en analogía con el universo, y con su época; para lo cual no le sirven el Latín y el Griego.” Martí, J. (1884) Reforma esencial en el programa de las Universidades Americanas. La América, Nueva York. En José Martí, Obras Completas, Tomo 8, p. 430.

Gimeno (2001:104) afirma que la cultura proporciona un sentido del "nosotros" como miembros de un grupo social que tiene una trayectoria histórica, lo cual permite tener conciencia de ser continuadores de "otros", que son semejantes a nosotros. La cultura marca la línea de progreso del conjunto social y de sí misma, a partir de la cual se expresan los valores, las pautas normativas indicadoras de por dónde y hacia dónde debe orientarse el desarrollo de los diferentes rasgos de la cultura y de los individuos, así como la elaboración de ideales, entre los que se cuentan los relativos a las formas deseables de relación social, cuya consecución necesita del apoyo, reflexión y transformación de los contenidos culturales en los que está implicada la educación.

Martí es sensible a las tensiones y a la experiencia de lo inacabado que se hacen presentes a la juventud en el escenario de las relaciones sociales, las que posibilitan asumir el cambio como la condición permanente de la transformación social. La educación tendría que potenciar en las personas la necesidad de ese cambio a favor del mejoramiento de las realidades sociales. Asumir el cambio es prepararse a lo contingente: 
La dramática situación de las generaciones actuales radica en que tienen que vivir en un medio social en que las costumbres, las ideas, los valores, la dinámica de la vida en el orden material -iy en lo social!-, no son estables, por el contrario, cambian con un ritmo como jamás se dio en ninguna etapa histórica de cultura alguna. Cambio en las relaciones humanas, cambio en los vínculos sociales, cambio en las costumbres, cambio en el uso de instrumentos, cambio en la estructura social y económica; por lo tanto, cambio en el trabajo, cambio en el ritmo de vida, distinto modo de servirse del espacio del tiempo, distinta manera de estimar los valores sociales, los conocimientos. (Almendros, H:1997: XII).

El incorporar la educación como una necesidad para el cambio social es prioridad del Estado o de las naciones. Martí muestra su interés para que la educación haga realidad una sociedad democrática que garantice el acceso a la población. Para él esta convicción no es un privilegio, sino un derecho de todos. Lo anterior coincide con la posición actual de UNESCO en torno a la discusión sobre una educación para todos:

El plan de reforma de la enseñanza que el ministro ha abordado con tan brava decisión y tan claro sentido, ha partido de donde había que partir; de un principio social que pide que en una democracia la educación no sea privilegio de unos y derecho negado de otros, sino educación para todos los ciudadanos de la República. Y ya se ha visto que el vasto plan de creación de escuelas para todos los niños que no las tenían, en un esfuerzo tan generoso que no lo hay igual relativamente, que sepamos, en ningún país del mundo. (Almendros, H:1997: VII).

Dewey (1998:278) afirma que la educación es el proceso mediante el cual puede realizarse la transformación necesitada, la cual parte de una reflexión comprometida con lo que es deseable, siendo la teoría de la educación una filosofía, que se consolida como una práctica deliberadamente dirigida.

\section{Educación para todos}

Visionariamente Martí reconoce que no basta con ofrecer escuelas para todas las personas, como el ingrediente de cambio en la dinámica social, esta acción debe estar acompañada de una reflexión cualitativa sobre el proyecto de una sociedad que se espera fortalecer o construir. Dicha reflexión es el camino para gestar un curriculum escolar, en sentido amplio, que promueva una sociedad diferente, producida al compás de un proyecto social capaz de asumir las exigencias de los actores sociales, lo anterior obedece a la elección de enfoques educativos que respondan a ese proyecto.

Gimeno y Pérez (2000:146) señalan que el curriculum alude a los contenidos del proyecto educativo y de la enseñanza que están presentes en distintos niveles y modalidades que cumplen funciones semejantes y, en parte, muy distintas. La escolarización cumple fines muy diversos. Esos fines educativos tienden a diversificarse o traducirse en proyectos que implican interpretaciones diferentes de las finalidades educativas.

El curriculum escolar tiene la tarea de dibujar al ser humano y a la sociedad que idealmente se espera formar desde el proceso educativo. Por tal razón la elección de las orientaciones pedagógicas, didácticas y contenidos curriculares va de la mano con el proyecto de sociedad que se espera construir a partir de éste. Conforme con las propuestas liberales, Martí apuesta por la pertinencia de lo actual frente a la tradición en el diseño de ese curriculum y lo propone como una tarea de la educación para que garantice los medios teóricos, metodológicos y prácticos que mejoren las condiciones de vida de las personas.

Este curriculum al formar parte de un proyecto social se consolida a lo largo del proceso educativo desde la primaria hasta la universidad, en las modalidades formales e informales, como parte de una educación pública que propicia un acercamiento permanente del curriculum a las exigencias sociales y a las aspiraciones humanas más trascendentales, por eso se preocupa por atender de la preparación en las áreas artísticas, físicas y especialmente científicas: 
Al mundo nuevo corresponde la Universidad nueva. A nuevas ciencias que todo lo invaden, reforman y minan nuevas cátedras.

Es criminal el divorcio entre la educación que se recibe en una época, y la época. Educar es depositar en cada hombre toda la obra humana que le ha antecedido; es hacer a cada hombre resumen del mundo viviente, hasta el día en que vive: es ponerlo a nivel de su tiempo, para que flote sobre él, y no dejarlo debajo de su tiempo, con lo que no podría salir a flote; es preparar al hombre para la vida." Martí, J. (1883) Escuela de Electricidad. La América, Nueva York. En José Martí, Obras Completas, Tomo 8, p. 281.

\section{Educación y equidad en las oportunidades}

El éxito de la educación como un espacio para preparar al ser humano para la vida, empieza a constituirse como tal en la medida en que ésta pueda albergar a cualquier persona en el proceso educativo. En el amplio espectro de los actores sociales se encuentran los estudiantes, los trabajadores y los grupos minoritarios como las mujeres y las personas con necesidades educativas especiales. Al respecto Dewey (1998:58) aporta que la necesidad de preparar para una vida en continuo desarrollo se requiere hacer la experiencia educativa presente significativa, porque el presente se funde con el futuro.

En el proyecto educativo martiano la presencia de los actores sociales está involucrada en las acciones educativas. Son parte integral para el cambio social, por eso el sistema educativo, en general, requiere ofrecer espacios reales para el desarrollo personal y profesional de los distintos actores sociales. Al respecto Martí recuerda las experiencias de la Liga de Nueva York un espacio de educación no formal para equilibrar el proceso educativo formal en la vida de los trabajadores.

La Liga de Nueva York es una casa de educación y de cariño, aunque quien dice educar, ya dice querer. En la Liga se reúnen, después de la fatiga del trabajo, los que saben que sólo hay dicha verdadera en la amistad y la cultura; los que en sí sienten o ven por sí que el ser de un color o de otro no merma en el hombre la aspiración sublime; los que no creen que ganar el pan en un oficio, da al hombre menos derechos y obligaciones que los de quienes lo ganan en cualquiera otro; los que han oído la voz interior que manda tener encendida la luz natural (...) Martí, J. (1892) Los Lunes de "La Liga". Patria, NuevaYork. En José Martí, Obras Completas, Tomo 5, p. 252.

Ese tipo de espacio educativo requiere poner en marcha condiciones didácticas más afines a la educación no formal y andragógica. Esta perspectiva es descrita por Martí al narrar la experiencia dinámica de construcción de conocimiento que ocurre en La Liga, en donde cada uno de los asistentes se constituye en mediador del proceso de autodidaxia:

A leer y escribir aprenden unos en la mesa, y otros, estudiándose y corrigiéndose los ensayos, bracean en lo más hondo del corazón humano, y buscan, para la luz del juicio y el bien del país, lo oculto y verdadero que apenas se entrevé en las páginas de la historia. No es una casa de creyentes de profesión, ni de rebeldes por oficio, sino donde se va con la modestia, y donde se sale con la verdad; donde los hombres, en vez de darse de dentelladas por los puestos, se los quitan de encima, para poder aprender más libremente, o toman de propósito el puesto más difícil; donde los ahorros del día, ni al juego van, que es gusto propio de la gente incapaz y egoísta, ni al prurito excesivo de andar de petrimetre, hecho todo una rosa y un charol, ni a esos muchos quehaceres de la frivolidad que son más cansados y más costosos que los de los afectos y el entendimiento; sino a mantener encendido el hogar de la aspiración, a tener un rincón grato y honrado donde las mentes se pongan a calentar en torno al fuego, y no las manos inútiles, a comprar los días de la recepción vinos y dulces para las amantes compañeras. Martí, J. (1893) Noche hermosa de La Liga. Patria, Nueva York, 4 de noviembre de 1893. En José Martí, Obras Completas, tomo 5, p. 267-270.

La situación descrita también resuena al otorgarle la participación permanente de las mujeres en el proceso educativo. Martí reconoce la capacidad intelectual de niñas y niños como garante de la equidad de oportunidades para mejorar la calidad de vida y las condiciones sociales, remarca la necesidad del intercambio personal como espacio de enriquecimiento mutuo. Si bien es cierto que la visión feminista de este autor no es realmente innovadora y 
revolucionaria, si merece ser destacada por su espíritu liberal con el consecuente apoyo a la reivindicación de las diferencias humanas y socioculturales.

... no hay diferencia alguna en la capacidad intelectual de los niños de uno u otro sexo, sometidos a la misma educación y sistema, y a las mismas influencias exteriores. Por igual y con estricta justicia, se han tenido que repartir los premios del colegio entre niños y niñas, y cuando ha habido exceso de alguna parte, ha sido a favor de las niñas. Para ese observador, no hay más diferencia por razón del sexo entre sus alumnos, que por razón del color de sus cabellos, en cuanto se les considere por sus capacidades como alumnos. Cree que si los niños aprovechan grandemente del trato de las niñas, de las cuales adquieren perspicacia, generosidad y dulzura, a las niñas es aún más útil el trato de los niños, que las libra de ese encogimiento, falta de trato y desconocimiento del espíritu de los hombres que suele causar luego tan grandes e irremediables infortunios en su vida. Martí, J. (1882) De Sección constante, La Opinión Nacional, Caracas. Obras Completas, tomo 23. p. 270-271. En Almendros, H. Ideario Pedagógico, La Habana: Editorial Pueblo y Educación, 1997, p. 101.

La equidad de oportunidades aparece en el discurso educativo contemporáneo como una prioridad para responder a las necesidades educativas especiales. Esta situación es comprendida por la posición de Martí cuando describe su encuentro con una escuela de sordomudos, recalca no sólo la pertinencia del esfuerzo, sino también el papel del educador en la experiencia educativa.

Nacidos como cadáveres, el amor los transforma, porque la enseñanza a los sordomudos es una sublime profesión de amor. Se abusa de esta palabra sublime; pero toda ternura es sublimidad, y el sordomudo enseñado es la obra tenaz de lo tierno. La paciencia exquisita, el ingenio excitado, la palabra suprimida, elocuente el gesto, vencido el error de la naturaleza, y vencedor sobre la materia torpe el espíritu benévolo, por la obra de la calma y de la bondad. El profesor se convierte en la madre: la lección ha de ser una caricia, todo niño lleva en sí un hombre dormido; pero los sordomudos están encerrados en una triple cárcel perpetua. Inevitablemente las lágrimas se agolpaban a los ojos en el examen de sordomudos de antier. Martí, J. (1875) La Escuela de Sordomudos. Revista Universal. En José Martí, Obras Completas, Tomo 6, p. 353.

\section{Educación y cambio social}

Martí está convencido de la importancia de la educación para transformar las condiciones políticas de la sociedad. Oportunamente analiza las implicaciones del acceso educativo no sólo en una dimensión local, sino también regional. Estas las aborda alrededor de las experiencias que conoce en sus viajes, lo que le permite percibir la relevancia que al interior de la sociedad genera las experiencias educativas, así como la visión de un sentir americanista que revalore la historia y la pertinencia del quehacer intelectual que puede pensar desde sus propios orígenes la realidad social.

En este sentido se suscribe las ideas expuestas por Pérez (2003:3), en las que se afirma que Martí defiende la educación como acto civilizatorio y sobre todo como acto político, afirmaciones que caracterizan a su filosofía de la educación, justificadas por un concepto de cultura que incorpora una relación dialéctica entre "el desarrollo cultural de los pueblos, con su mayor o menor disfrute de libertad, y en esta apreciación estaba unida a la acción práctica, revolucionaria, por transformar la realidad".

\section{La transformación social una exigencia latinoamericana de la educación}

La visión del proceso educativo martiano muestra un papel relevante en la inserción de los individuos a las exigencias sociales, especialmente cuando se trata de entrar en un juego sociocultural en una sociedad ajena. Esta es una preocupación constante en la medida en que el mundo experimenta una continua emigración $\mathrm{y}$, con su consecuente conflicto intercultural. Esta posición la recoge Martí en su visita al Colegio Tomás Estrada Palma en Central Valley de Nueva York: 
El fin de la educación no es hacer al hombre nulo, por el desdén o el acomodo imposible al país al que ha de vivir, sino para prepararlo para vivir bueno y útil en él. El fin de la educación no es hacer al hombre desdichado, por el empleo difícil y confuso de su alma extranjera en el país en que vive, y de que vive, sino hacerlo feliz, sin quitarle, como su desemejanza del de su país le quitaría, las condiciones de igualdad en la lucha diaria con los que conservan el alma del país. Es espectáculo lamentable el del hombre errante e inútil que no llegas jamás a asimilarse el espíritu y métodos del país extranjero en grado suficiente para competir en él con los naturales que lo miran siempre como extraño, pero que se ha asimilado ya bastante de ellos para hacerle imposible o ingrata la vida en un país del que se reconoce diferente, o en el que todo le ofende la naturaleza inflada y superior. Son hombres sin brújula, partidos por mitad, nulos para los demás y para sí, que no benefician al país en el que han de vivir y que no saben beneficiarse de él. Son, en el comercio arduo de la vida, comerciantes quebrados." Martí, J. (1892) El colegio de Tomás Estrada Palma en Central Valley. Patria, Nueva York. En José Martí, Obras Completas, Tomo 5, p. 261.

Reconoce la participación de los latinoamericanos en el escenario educativo de Nueva York, en el que destacan haciendo honor a sus raíces de procedencia. Se percibe el sentimiento de optimismo que embarga a Martí cuando descubre que los premios educativos son obtenidos por jóvenes provenientes de estos países.

Esta experiencia le permite a Martí reflexionar sobre la pertinencia de repensar una mentalidad social en la que la formación recibida obstruye el descubrimiento de las posibilidades con que puede fortalecerse la realidad de los países latinoamericanos. El modelo de formación se apoya en el conocimiento de una intelectualidad procedente de centros hegemónicos, que perciben a estos países todavía como núcleos coloniales, con lo que significa reflejarse en un aparente espejo de inferioridad. Por tal razón la educación debería replantear esa formación en función de las exigencias actuales de la época, en donde es importante esforzarse por asumir el compromiso por una sociedad latinoamericana:
¡Ohi i si a estas inteligencias nuestras se las pusiese a nivel de su tiempo; si no se les educace para golillas y doctos de birrete de los tiempos de audiencias y gobernadores, si no se les dejase, en su anhelo de saber, nutrirse de vaga y galvánica literatura de pueblos extranjeros medio muertos; si se hiciese el consorcio venturoso de la inteligencia que ha de aplicarse en un país; si se preparase a los suramericanos, no para vivir en Francia, cuando no son franceses, ni en los Estados Unidos, que es la más fecunda de estas modas malas, cuando no son norteamericanos, ni en los tiempos coloniales; cuando están viviendo ya fuera de la colonia, en competencia con pueblos activos, creadores, vivos, libres, sino para vivir en la América del Sur. Mata a su hijo en la América del Sur el que le da mera educación universitaria. Martí, J. (1884) Mente latina. La América, Nueva York. En José Martí, Obras Completas, Tomo 6, p. 25.

Un sentimiento brota de la consciencia de Martí sobre el papel de la educación en la sociedad latinoamericana. La experiencia de relegar el conocimiento y la apropiación de fuentes de saber indígena como una visión de mundo que ofrece otro punto de vista, igualmente importante, para el proceso educativo, que los modelos de formación que se basan en autores, cosmologías y fuentes filosóficas europeas o estadounidenses. Clama por el reconocimiento de esa otra fuente que conforma al ser latinoamericano, no en balde olvidada o relegada por lo que es visto como mejor por provenir de latitudes lejanas, marcadas por la conquista y la colonización que acometieron en estas tierras americanas.

No somos aun bastante americanos: todo continente debe tener su expresión propia; tenemos una vida legada, y una literatura balbuciente. Hay en América hombres perfectos en la literatura europea; pero no tenemos un literato exclusivamente americano. Ha de haber un poeta que se cierna sobre las cumbres de los Alpes de nuestra sierra, de nuestros altivos Rocallosos; un historiador potente más digno de Bolívar que de Washington, porque la América es el exabrupto, la brotación, las revelaciones, la vehemencia, y Washington es el héroe de la calma; formidable, pero sosegado; sublime, pero tranquilo. ¿Qué no hará entre nosotros el nuevo sistema de enseñanza? Los indígenas nos traen un sistema nuevo de vida. Nosotros estudiamos lo que nos traen de Francia; pero ellos nos revelarán lo que tomen de la naturaleza. De esas caras cobrizas brotará nueva luz. La enseñanza va a revelarnos a sí mismos. No nos dará vergüenza que un indio venga a 
besarnos la mano: nos dará orgullo que se acerque a dárnosla. Martí. J. (1875) "El proyecto de instrucción pública”, en Revista Universal, México. O.C., t. 6. p. 351-353. En Almendros, H. Ideario Pedagógico, La Habana: Editorial Pueblo y Educación, 1997. p. 41.

Llena de ilusión el descubrimiento de cambios importantes en el proceso educativo de los países centroamericanos. Especialmente aquellos que muestran el valor de la Universidad de San Carlos de Guatemala, así como los progresos de los sistemas educativos que incorporan la educación técnica, la formación de docentes y la ampliación del acceso a la instrucción pública. No obstante, a ello, se aúna un replanteamiento del curriculum, el cual incorpora la filosofía liberal, recogida en los principios de tolerancia y la utilidad práctica de los contenidos curriculares.

Y ¡cómo vivía antes, oligárquicamente gobernada, esta vasta República, (Guatemala) de extensiones tan fértiles de espíritus tan ricosi En míseras escuelas, enseñábanse apenas principios de doctrina, y Fleury, y moral cristiana, y santos cristianos, y un tanto, así como superfluo, de leer y de escribir. Ni lastimar, ni poetizar, son aquí mi misión; mi misión es contar. Hoy cada aldea tiene escuela; con sus manos fabrican sus padres la casa del maestro; del haber del hijuelo se priva el campesino porque aprenda de letras; aumenta en la ciudad los institutos, carácter grave; extiéndese en la Universidad el ya lleno programa; apréndense en la Escuela Politécnica, con hábitos militares, matemáticas, enseña la Escuela Normal, por práctico sistema de razón y propio juicio, a ser maestros; quinientos niños pueblan los salones del extenso Instituto Nacional; bien se enseña en San Francisco; del extranjero fueron traídos maestros y maestras; unos y otras enseñan tolerancia religiosa, dan instrucción realmente útil, vulgarizan los más recientes sistemas americanos y europeos". Martí, J. (1878) Guatemala, México. En José Martí, Obras Completas, Tomo 7, p. 154.

El compromiso de Martí por la educación se evidencia en su convencimiento de transformación personal y sociocultural, que significa dar la oportunidad y abrirse a la experiencia educativa para encontrar en los textos, un espacio de análisis que promete ser un camino fructífero para repensar la historia y orientar hacia otras formas de percibir, concebir y querer la realidad socioeconómica, cultural, política e histórica de los países latinoamericanos. Estas posibilidades se gestan en el sentir de los hombres y mujeres indígenas que tienen la oportunidad de ser partícipes del proceso educativo.

Aindiados, descalzos, huraños, hoscos, bruscos, llegan las soledades interiores niños y gañanes, y de pronto, por íntima revelación y obra maravillosa del contacto con la distinción y el libro, el melenudo cabello se asienta, el pie encorvado se adelgaza, la mano dura se perfila, el aspecto mohíno se ennoblece, la doblada espalda se alza, la mirada esquiva se despierta: la miserable larva se ha hecho hombre. Poco después asaltan la tribuna los libros históricos, los libros de agricultura, la flauta, el piano. Se dan en pensar en cosas graves, a dudar, a inquirir, a examinar. Hablar de Bolívar, de los hombres patrios, del buen gobierno que los educa, ¡del porvenir vasto que espera a su -como ellos dicen- querida Guatemalaj. Yo los veo, yo los impulso, yo los aliento-. De esos hombres saldrán, más tarde, algunos grandes hombres. Martí, J. (1878) Guatemala, México. En José Martí, Obras Completas, Tomo 7, p. 154.

Este es el convencimiento que guía a Martí para sostener la importancia del proceso educativo como un mediador social que puede promover una "revolución radical" en la sociedad, no obstante, para que ésta sea viable, se requiere que la educación en sí misma se transforme, es decir cambie sus orientaciones teóricas y didácticas, así como sus fines y su misión como parte de un proyecto político.

En nuestros países ha de hacerse una revolución radical en la educación, si no se les quiere ver siempre, como aún se ve ahora a algunos, irregulares, atrofiados y deformes, como el monstruo de Horacio: colosal la cabeza, inmenso el corazón, arrastrando los pies flojos, secos y casi en hueso los brazos. Contra la Teología, Física; contra la Retórica, Mecánica; contra preceptos de la lógica, que el rigor, consistencia y trabazón de las artes enseña que mejor que los degenerados y confusos textos de pensar de las escuelas, preceptos agrícolas, como quién señala, pues una vía, señalamos la Compañía Excelsior de San Luis. Martí, J. (1883) Escuela de Mecánica, La América, Nueva York. En José Martí, Obras Completas, Tomo 8, p. 279. 


\section{Libertad de enseñanza y enseñanza obligatoria}

Los conceptos martianos de cultura y educación se vinculan estrechamente con el progreso social, el desarrollo y la formación progresiva de la libertad que caracterizan de modo sustancial ese progreso. Esta visión está presente en el proyecto educativo costarricense de principios del siglo XX, en el que "la libertad es la condición y la posibilidad más legítima del hombre. (...) El proceso educativo debe proporcionar el ambiente más propicio para el cultivo de la libertad en los niños y en los jóvenes, libertad con responsabilidad”. (Dengo, M:1995:14).

Siguiendo el espíritu liberal de su época, Martí pregona dos principios constitutivos de la educación como un medio de transformación social. Se trata de la libertad de enseñanza y la enseñanza obligatoria, los cuales son propuestos pensando en el papel de la libertad en la vida personal y en su carácter emancipatorio, así como principio fundante de una sociedad. Dos frases del autor explican esta perspectiva:

La felicidad general de un pueblo descansa en la independencia individual de sus habitantes. Una nación libre es el resultado de sus pobladores libres. Martí, J.(1883) Escuela de artes y oficios, La América, Nueva York. En José Martí, Obras Completas, Tomo 8, p. 284.

Desde esa visión, la sociedad exige modelos educativos más cercanos a la población, a los intereses de cada individuo, así como a la resolución creativa de conflictos cotidianos, más afin a una educación que tiende a ofrecer opciones claras y visibles en el proceso de formación, este es el caso de la educación técnica y su influencia en el desarrollo de una concepción educativa liberal que emana los ideales de herencia napoleónica.

Las Escuelas de Artes y Oficios ayudan a resolver el problema humano, que se establece ahora con datos nuevos, desde que van faltando aquellos árboles antiguos, Monarquía e Iglesia, bajo cuyas ramas tenían cómoda vida tantos hombres. Ya, ni cortesanos, ni frailes. Los tiempos están revueltos; los hombres están despiertos, y cada cual ha de labrarse con sus manos propias la silla en que se sienta al festín de la fortuna. Ya no hay aquellas clases estables y hechas por donde se entraban las vidas como por cauces abiertos; ya no hay legiones de descalzos mendicantes; ni colmenares de pretendientes, jaunque de éstos aún hayi: ni regimientos de caballeros de matar, hurtar damas y servir; ni manadas de lacayos. Martí, J. (1883) Escuela de artes y oficios, La América, Nueva York. En José Martí, Obras Completas, Tomo 8, p. 284.

Hay una exigencia real que acompaña esta iniciativa. Se tata de favorecer a la mayor parte de los miembros de una sociedad con los beneficios del proceso de educativo. Con esta visión prospectiva apoya la creación de un proyecto nacional de educación pública obligatoria. Esta situación lo lleva a avalar la propuesta del mexicano Benito Juárez para su nación, dado que garantiza el inicio de un proceso de alfabetización con alcances transformadores de las condiciones de calidad de vida de los sectores sociales más desprotegidos:

Toda idea se sanciona por sus buenos resultados. Cuando todos los hombres sepan leer, todos los hombres sabrán votar, y, como la ignorancia es la garantía de los extravíos políticos, la conciencia propia y el orgullo de la independencia garantizan el buen ejercicio de la libertad. Un indio que puede leer puede ser Benito Juárez; un indio que no ha ido a la escuela, llevará perpetuamente en cuerpo raquítico un espíritu inútil y dormido. Hasta estas palabras me parecen inútiles: tan invulnerable y tan útil es para mí la enseñanza obligatoria. Los artículos de la fe no han desaparecido: han cambiado de forma. A los del dogma católico han sustituido las enseñanzas de la razón. La enseñanza obligatoria es un artículo de fe del nuevo dogma. Martí, J. (1875) El proyecto de instrucción pública, Revista Universal, México. En José Martí, Obras Completas, Tomo 6, p. 351.

El carácter emancipador de la educación, lo lleva a valorar la instrucción pública como el mecanismo social que permite la creación de ideas y proyectos, tendientes a transformar las visiones y las condiciones de vida de la población:

Un proyecto de instrucción pública es una sementera de ideas: cada mirada al proyecto suscita pensamientos 
nuevos. Martí, J. (1875) El proyecto de instrucción pública, Revista Universal, México. En José Martí, Obras Completas, Tomo 6, p. 353.

Recuperando la visión ilustrada, el proyecto educativo martiano está impregnado de un sentimiento reivindicativo de la educación como escenario de transformación de la persona. No obstante esa oportunidad mueve a la sociedad en busca de un mayor espectro de posibilidades. Sin duda refleja esta visión en su compromiso por una educación popular como aliada del éxito de las naciones por encontrar su rumbo, un resabio de su deseo por la independencia de Cuba y el mejoramiento de las condiciones socioeconómicas y culturales de la sociedad en el marco de un proceso educativo que garantiza el acceso a la mayor parte de la población.

En este sentido la universidad latinoamericana se convierte en un proyecto político, como espacio de creación de consciencias y de consolidación de las perspectivas latinoamericanas en el desarrollo de cada país. Los políticos latinoamericanos tienen que encontrarse con su realidad e identidad, expresada en la necesidad de vivir con orgullo de la propia cultura:

Conocer el país, y gobernarlo conforme al conocimiento, es el único modo de librarlo de tiranías. La Universidad europea ha de ceder a la Universidad americana. La historia de América, de los incas de acá, ha de enseñarse al dedillo, aunque ni se enseñe la de los arcontes de Grecia. Nuestra Grecia es preferible a la Grecia que no es nuestra. Nos es más necesaria. Los políticos nacionales han de reemplazar a los políticos exóticos. Injértese en nuestras repúblicas el mundo; pero el tronco ha de ser el de nuestras repúblicas. Y calle el pedante vencido; que no hay patria en que pueda tener el hombre más orgullo que en nuestras dolorosas repúblicas americanas. Martí, J. (1891) Nuestra América, El Partido Liberal, México. En José Martí, Obras Completas, Tomo 6, p. 15.

El compromiso político de los pueblos latinoamericanos radica en tomar consciencia de su injerencia en los procesos socioculturales que marcan el sentir de un pueblo por encontrar su propio valor, solo así éstos consiguen su independencia:
La independencia de los pueblos y su buen gobierno vienen sólo cuando sus habitantes deben su subsistencia a un trabajo que no está a la merced de un regalador de puestos públicos, que los quita como los da y tiene siempre en susto, cuando contra él armados en guerra, a los que viven de él. Esa es gente libre en el nombre; pero, en lo interior, ya antes de morir, enteramente muerta. Martí, J. (1884). La Escuela de artes y oficios de Honduras, La América, Nueva York. En José Martí, Obras Completas, Tomo 6, p. 16.

El fortalecimiento de los procesos educativos en cada país y en la región latinoamericana coadyuvaría a afianzar la convicción por trazar un camino propio para cada uno de éstos y definir un rumbo preciso de una región sometida a la imposición de otras naciones, no mejores a nuestros países, sólo diferentes. Así pues se requiere innovar los procesos de educación asociados con el mejoramiento de las áreas de mayor incidencia en la realidad de los países latinoamericanos: la agricultura, las artes y los oficios:

Pues así como se manda a los niños de Hispanoamérica a aprender lo que en sus tierras, por elementales que sean, aprenderían mejor, con riesgo de perder aquel aroma de la tierra propia que da perpetuo encanto y natural y saludable atmósfera a la vida; así como se sirve en oficinas de comercio, a adquirir tras largos años un puñado de prácticas vulgares que caben en una cáscara de nuez, y que aprenden de igual modo en la casa propia, sin perder lo que se pierde, siempre en la ajena, así sin tanto riesgo y con mayor provecho, deben enviar los gobiernos a los agricultores ya entendidos; y los padres, a los hijos, a quienes quieran hacer beneficio verdadero con enseñarles el cultivo de la tierra la única fuente absolutamente honrada de riqueza; y los hacendados, a hombres capaces de llevar luego a sus haciendas las mejoras que en las de acá vean, a estudiar la agricultura nueva en los cultivos prósperos, a vivir durante la época de una a varias cosechas en las haciendas donde se siguen los sistemas recientes, a adquirir en todos sus detalles, sin lo que no es fructífero, el conocimiento personal y directo de las ventajas de los métodos e instrumentos modernos. Martí, J. (1883). A Aprender en las Haciendas, América, Nueva York, En José Martí, Obras Completas, Tomo 8, p. 276.

Traspasando la frontera de lo cotidiano, la educación es clave para garantizar la vida digna de las personas y, en consecuencia, la oportunidad de los pueblos 
por hacer valer su propia dignidad, sin importar las condiciones socio-económicas, en manos de una ciudadanía formada no sólo en conocimientos y oficios, sino también en derechos fundamentales que pueden ejercer libremente en sus sociedades, lo cual es posible en la medida en que haya un cuerpo docente capaz de realizar su quehacer en cualquier lugar: aulas, campos o fábricas.

Pan no se puede dar a todos los que han menester, pero los pueblos que quieren salvarse han de preparar a sus hijos contra el crimen: en cada calle, un kindergarten: el hombre es noble, y tiende a lo mejor: el que conoce lo bello, y la moral que viene de ello, no puede vivir luego sin moral y belleza: la infancia salva: una ciudad es culpable mientras no es toda ella una escuela: la calle que no lo es, es una mancha en la frente de la ciudad: ¿a qué ir con la frente coronada de palacios, y los gusanos hasta las rodillas?: al patriotismo literario, hay que oponer el patriotismo activo: de salmos y chocolates eran las Misiones de antes, las de ahora han de ser de kindergarten y zapatos: se han de reclutar soldados para el ejército, y maestros para los pobres: debe ser obligatorio el servicio de maestros, como el de los soldados: el que no haya enseñado un año, que no tenga el derecho de votar: preparar un pueblo para defenderse, y para vivir con honor, es el mejor modo de defenderlo. Martí, J. De "Política internacional y religión”, Obras Completas, tomo 12, p. 414-415. En Almendros, H. Ideario Pedagógico, La Habana: Editorial Pueblo y Educación, 1997, p. 143.

Sin duda la visión descrita del proceso educativo de Martí sostiene como prioridad un cambio en el modelo educativo tradicionalista, entendido como una enseñanza formal, elitista y adscrito a posiciones teóricas y políticas europeizantes y anglosajonas. No obstante el modelo educativo martiano tiene fuentes de reflexión teórica de las tendencias mencionadas, se caracteriza por marcar un derrotero desde las necesidades, intereses y expectativas de las naciones latinoamericanas.

\section{Crítica al modelo educativo tradicionalista}

El cambio y la adaptación de los procesos educativos en las distintas modalidades y niveles con las necesidades de los individuos para que puedan asumir el dinamismo de los tiempos, lo que la sociedad exige de ellos, lo que de ellos reclama, están claramente expresadas en Martí, repetidamente en sus escritos. La época en que él vivió y escribió comienza ya a sentir esa dramática necesidad de adaptación del individuo a las nuevas condiciones de vida; lo que, a la postre, pone de manifiesto la insuficiencia de una escuela estática y tradicionalista en un mundo que empieza a requerir otro tipo de individuo, con otras posibilidades de pensamiento, por ello la educación tendría que cambiar en relación con la época.

El proyecto educativo martiano responde a una visión más cercana a la potenciación de las distintas áreas de saber, el fortalecimiento de oportunidades de formación para el trabajo, lo que incluye el reconocimiento y la pertenencia a un país y a una sociedad en construcción en la que se requiere un ciudadano que asuma su compromiso por los intereses de la sociedad. Persigue fomentar una educación conforme a la vida, a la realidad cotidiana del individuo, que al mismo tiempo le fuera posible conocer, desarrollar y propiciar el ejercicio lúdico y artístico del pensamiento. Desde este panorama lo más importante es sustituir el modelo de formación clásica, centrada en una orientación de lectura del pasado, como único sendero de preparación académica y de inserción en la sociedad.

En consonancia con lo anterior, Dewey (1998:91) afirma que la educación es un proceso social en el que se involucran diferentes sociedades, las cuales requieren formar criterios para la crítica y la construcción de opciones educativas, lo que implica elaborar un ideal social particular.

El cuestionamiento al enfoque de la educación tradicional revela otra preocupación del modelo martiano, a saber, el interés por la formación científica desde niveles primarios hasta la educación superior en las áreas técnicas o universitarias. 
Sin duda se trata de la incorporación paulatina del modelo de formación de herencia napoleónica, según el cual la presencia del área científica es indispensable en la educación, como consecuencia de ello las universidades incluyen las carreras profesionales en campos afines al desarrollo científico y tecnológico, asimismo el curriculum escolar de la educación general básica y diversificada incluye el área de las ciencias como una disciplina básica del proceso educativo:

Como quién vuelve del revés una vaina de espada, se ha de cambiar de lleno el sistema transitorio y vacilante de educación moderna. Mas, no habrá para pueblo alguno crecimiento verdadero, ni felicidad para los hombres, hasta que la enseñanza elemental no sea científica: hasta que enseñe al niño el manejo de los elementos de la tierra de que ha de nutrirse cuando hombre; hasta que, cuando abra los ojos para ver un arado, sepa que puede uncirlo, como un buey en otro tiempo, jun rayoj. Que de aquí a poco, la electricidad moverá arados. Asombra que con tanto hombre que junta polos y saca fuerza de los ríos y cascadas, no se haya pensado aún en unir al yugo, en vez de una criatura viva que padece, un acumulador de Faure." Martí, J. (1883). Cartas de Martí, La Nación, Buenos Aires. En José Martí, Obras Completas, Tomo 9, p. 446.

Cabe destacar que esta visión del proceso educativo no deja de lado la importancia de la formación clásica en la literatura o en la filosofía, sólo que estas áreas de producción y reflexión no se piensan como exclusivas de dicho proceso, sino indispensables para la promoción de las capacidades lúdicas y artísticas:

Lo que queremos es que los niños sean felices, como los hermanitos de nuestro grabado; y que si alguna vez nos encuentra un niño de América por el mundo nos apriete mucho la mano, como a un viejo amigo, y diga donde todo el mundo le oiga: “"Este hombre de La edad de oro fue mi amigoi Martí, J. (1889) La Edad de Oro, Nueva York. En José Martí, Obras Completas, tomo 18, p. 301-303.

Lo anterior también implica una critica al modelo educativo tradicionalista, el cual se caracteriza por favorecer un aprendizaje memorístico en relación con una enseñanza que descontextualiza la importancia de los contenidos y su vínculo con la cotidianidad de los individuos. Por lo anterior, es importante contar con una enseñanza que promueva un acceso más lúdico a los conocimientos:

Una lectura no sujeta, antes distrae la atención: la naturaleza humana y sobre todo, las naturalezas americanas, necesitan que de lo que se presente a su razón tenga algún carácter imaginativo; gustan de una locución vivaz y accidentada; han menester que cierta forma brillante envuelva lo que es en su esencia árido y grave. No es que las inteligencias americanas rechacen la profundidad; es que necesitan ir por un camino brillante hacia ellas. Pudiera decirse que se pretende dar con las lecturas cierto carácter respetable a las clases orales, las clases no lo necesitan.- Los conocimientos se fijan más, en tanto que se les da una forma más amena". Martí, J. (1875). Clases Orales De Revista Universal, México. En José Martí, Obras Completas, Tomo 6, p. 235.

La pertinencia de una educación que se hace contextual a la época y al desarrollo histórico de las sociedades, requiere de una revisión constante de los procesos socioculturales y de las tendencias educativas que promueven áreas de formación específicas, lo cual muestra la relación entre éstas y la relación con la sociedad y el estado. En este caso, Martí enfatiza la necesidad de una formación técnica, la cual está asociada con las necesidades y características socioculturales de cada país latinoamericano, por ejemplo el fortalecimiento de la educación agrícola, por tratarse de un sector productivo vital en las economías de los países centroamericanos. El modelo tradicional se caracteriza por estar vinculado con una formación más academicista que responde a los intereses y expectativas de una cotidianidad más urbana que rural.

En los pueblos que han de vivir de la agricultura, los gobiernos tienen el deber de enseñar preferentemente el cultivo de los campos. Se está cometiendo en el sistema de educación de América Latina un error gravísimo: en pueblos que viven casi por completo de los productos del campo, se educa exclusivamente a los hombres para la vida urbana, y no se les prepara para la vida campesina. Y como la vida urbana sólo 
existe a expensas y por virtud del campestre, y de traficar en sus productos, resulta que con el actual sistema de educación se está creando un gran ejército de desocupados y desesperados; se está poniendo una cabeza de gigante a un cuerpo de hormiga. Y cada día, con la educación puramente literaria que se viene dando a nuestros países se añade a la cabeza, y se quita el cuerpo. Martí, J. (1884). La próxima exposición de New Orleans, La América, Nueva York. En José Martí, Obras Completas, Tomo 8, p. 369.

El reto del proyecto educativo martiano radica en buscar un equilibrio entre la formación científica y la humanista, dado que no puede pensarse en un individuo que no explore y haga suyo lo que se enseña para transcender su cotidianidad:

La mente humana, artística y aristocrática de suyo, rechaza a la larga y sin gran demora, a poco que se la cultive, cuanta reforma contiene elementos brutales e injustos. La educación suaviza más que la prosperidad: no esa educación meramente formal, de escasas letras, números dígitos y contornos de tierra que se da en las escuelas demasiado celebradas y en verdad estériles, sino aquella otra más sana y fecunda, no intentada apenas por los hombres, que revela a estos los secretos de sus pasiones, los elementos de sus males, la relación forzosa de los medios que han de curarlos al tiempo y naturaleza tradicional de los dolores que sufren, la obra negativa y reaccionaria de la ira, la obra segura e incontrastable de la paciencia inteligente. Martí, J. (1883). Prólogo al libro Cuentos de hoy y de mañana de Rafael Castro Palomino, La América, Nueva York. En José Martí, Obras Completas, Tomo 5, p. 101-102.

\section{Sujeto del proceso educativo}

Pérez (2003:3) afirma que la idea de ser humano del proyecto educativo martiano se apoya en una visión dialéctica en la que hay una búsqueda constante del desarrollo de la propia naturaleza humana. $\mathrm{Pa}-$ ra lograr este propósito plantea un sistema de formación integral donde se combinan los procesos de conocer, pensar, apreciar y actuar como vías para fortalecer principios y valores a partir de la formación y expresión de emociones y sentimientos.

¿De donde viene que con ser tan patente el cuidado con que aquí se atiende a la instrucción pública, tan vastos los recursos, tan numerosos los maestros, tan hábiles y bellos los libros, den por resultado general niños fríos y torpes que después de seis años de escuela dejan los bancos sin haber contraído gustos cultos, sin la gracia de la niñez, sin el entusiasmo de la juventud, sin la afición a los conocimientos, sin saber por lo común más, cuando mucho saben, que leer a derechas, escribir vulgarmente, calcular en aritmética elemental, y copiar mapas? Martí, J. (1886) De "Cartas de Martí. Nueva York en otoño, La Nación, Buenos Aires, Obras Completas, tomo 11, p. 80-86. En Almendros, H. Ideario Pedagógico, La Habana: Editorial Pueblo y Educación, 1997, p. 15.

Acertadamente Martí sabe que todo proceso educativo que resulta innovador en la enseñanza, requiere estar acorde con el espíritu de la época, no basta con pensar en las condiciones socioculturales, políticas y económicas, también es necesario referirse al sujeto educativo, atribuyéndole las potencialidades y oportunidades que se requieren para hacer frente a la transformación en el campo educativo. Este autor reconoce que las condiciones materiales y la producción de textos de alta calidad no son, en general, determinantes para ese propósito.

El derrotero del proceso educativo debería ser el cambio de los espacios de enseñanza y aprendizaje, porque la apatía, el desinterés, el menosprecio, las actitudes de estudiantes y docentes, con frecuencia, muestran el sentido negativo acerca de dicho proceso que emerge de las experiencias cotidianas de ambos en centros educativos aficionados a los modelos tradicionales de la educación. Una de las consecuencias más interesantes de esta situación, es la deserción, problema vigente y agudo en nuestro sistema educativo.

Los centros educativos se enfrentan con niños y jóvenes que no sólo requieren seguir cursos para aprobarlos y con ello obtener alguna certificación. Antes de esto es necesario que se tenga presente su tarea en la formación de un proyecto de vida fundamentado en valores socialmente deseables para el desarrollo personal y social, especialmente su interés hacia el trabajo y las posibilidades que le ofrece, por ejemplo, 
mejores condiciones de vida y acceso a otras situaciones socioculturales. Curiosamente este aspecto es parte del proyecto educativo liberal; en el caso del sistema educativo nacional y de la idiosincrasia del costarricense, este proyecto se revela en las acciones políticas tomadas a finales del siglo XIX.

El niño desde que puede pensar, debe pensar en todo lo que ve, debe padecer por todos los que no pueden vivir con honradez, debe trabajar porque puedan ser honrados todos los hombres, y debe ser un hombre honrado. El niño que no piensa en lo que sucede a su alrededor, y se contenta con vivir, sin saber que vive honradamente, es como el hombre que vive del trabajo de un bribón, y está en camino de ser un bribón. Martí, J. (1889) Tres héroes. En José Martí, Obras Completas, tomo 18, p. 304.

Martí aboga por una educación que permita la formación integral del ser humano, en lo cognoscitivo y lo afectivo, en este último aspecto se apunta al conocimiento y disfrute de lo estético. Se apoya en la visión humanista heredada de la filosofía clásica que traza como proyecto social la construcción de un ideal de ser humano, intención que ilustra mediante un acercamiento a la explicación aristotélica. Este ideal se promueve con un proceso continuo en la educación preescolar, primaria, secundaria y universitaria.

Cuando no se ha cuidado el corazón y la mente en los años jóvenes, bien se puede temer que la ancianidad sea desolada y triste. Bien dijo el poeta Southey, que los primeros veinte años de la vida son los que tienen más poder en el carácter de un hombre. Cada ser humano lleva en sí un hombre ideal, lo mismo que cada trozo de mármol contiene en bruto una estatua tan bella como la que el griego Praxiteles hizo del dios Apolo. La educación empieza con la vida, y no acaba con la muerte. El cuerpo es siempre el mismo, y decae con la edad; la mente cambia sin cesar, y se enriquece y perfecciona con los años. Pero las cualidades esenciales de ese carácter, lo original y enérgico de cada hombre, se deja ver desde la infancia en un acto, en una idea, en una mirada. Martí, J. (1889) Tres héroes. En José Martí, Obras Completas, tomo 18, p. 390-391.

El papel del docente es fundamental en el desarrollo personal de sus estudiantes, la transparencia del trato, del contenido de sus lecciones y la actitud frente a lo que enseña, son una garantía para contribuir a la formación de un ser humano que se perciba integralmente y se asuma como gestor social.

A los niños no se les ha decir más que la verdad, y nadie debe decirles lo que no sepa que es como se lo esta diciendo, porque luego los niños viven creyendo lo que les dijo el libro o el profesor, y trabajan y piensan como si eso fuera de verdad, de modo que si sucede que era falso lo que les decían, ya les sale la vida equivocada, y no pueden ser felices con ese modo de pensar, ni que como son las cosas que de veras, ni pueden volver a ser niños, y empezar a aprenderlo todo de nuevo. Martí, J. (1889) La galería de las máquinas. En José Martí, Obras Completas, tomo 18, p. 500-501.

La experiencia de aprender-aprender y de aprender haciendo es parte de la iniciativa del proceso educativo martiano, especialmente por la capacidad de crear y expresar que estimulan a la libertad y a la individualidad del sujeto educativo.

El estudio es el carril; pero el carácter, la individualidad del niño, esa es la máquina. Y se ve que la libertad de la invención y el placer de crear por sí, estimulan, aun en las niñas que son de menos acontecimiento, el ingenio propio y la fuerza del carácter. Martí, J. (1889) De Nueva York, La Nación , Buenos Aires, 2 de agosto de 1889. En José Martí, Obras Completas, tomo 12 , p. 241.

A lo anterior se aúna una característica fundamental de la práctica pedagógica: el amor y el diálogo. Se trata de supuestos de la mediación pedagógica que promueven una pertenencia significativa del aprendizaje. El aprendizaje requiere ser cercano al contexto particular de las regiones o de los países en que se desenvuelven los sujetos del proceso educativo, lo que hoy en día se analiza en la pedagogía diferenciada y en el interés por promover una pedagogía de la ternura. La crítica de Martí a los centros educativos que se preocupan por la inteligencia cognoscitiva, desvirtuando la formación humanista y la posibilidad de apropiarse de los valores de 
solidaridad, equidad y tolerancia; valores ligados a la medicación pedagógica y a las áreas de interés de las pedagógicas mencionadas, a las cuales se agrega la preocupación por una educación multicultural.

Si se repiensa el sujeto educativo, se insiste en la necesidad de contar con un ser humano que posea una formación integral en las dimensiones de lo moral, lo intelectual, lo físico y lo estético, las cuales son promovidas en la mediación pedagógica a través de la investigación, la retórica y la escritura, con lo que se cuestiona a una sociedad cada vez más centralizada en lo técnico, reduciendo la experiencia del proceso educativo a un contacto mecánico con el conocimiento, sin exploración lúdica y carente de la oportunidad de escribir las propias bitácoras del aprendizaje.

\section{Reflexiones finales}

El proyecto educativo de Martí propone una perspectiva transformadora, en la que se incorpora la necesidad de un saber técnico, científico, estético, humanista, cívico. Una formación integral del estudiante que participa de los procesos de enseñanza y aprendizaje en diferentes modalidades formal o no formal, así como niveles educativos desde preescolar hasta el universitario. Su filosofía de la educación muestra el alcance de un proyecto político que refleja los intereses teóricos y metodológicos del pensamiento liberal, ilustrado, así como emancipador. Estas características permiten valorar la vigencia en los actuales enfoques de educación de niños, jóvenes y adultos, así como la educación popular (Pérez:2003).

Para Martí el proceso pedagógico obedece a las circunstancias histórico concretas de cada sociedad, de cada grupo e individuo, lo cual se convierte en el medio de transformación social a través de la revisión constante del quehacer y de las políticas educativas. En este sentido propone métodos didácticos bastante amplios y sugerentes, basados en la experimentación, el diálogo y la expresión artística, lo cual garantiza la visión de un sujeto educativo integral y comprometido con una realidad sociocultural e histórica que puede cambiar y transcender, porque educarse es una experiencia continua en la vida. Lo anterior se concreta a través de la práctica docente que promueva el reconocimiento de las diferencias individuales, parta de las necesidades e intereses cognoscitivos de sus alumnos, trabaje con los saberes colectivos, fortalezca un pensamiento crítico que construye una conciencia histórica y social, así como el enriquecimiento de la práctica a través de la autorreflexión y el análisis, por lo que estimula el espíritu investigativo y el compromiso social, construye el nuevo conocimiento desde una perspectiva valorativa y se interesa por promover el cambio progresivo en la propia naturaleza de los sujetos.

Las potencialidades y vigencia del pensamiento educacional de José Martí, de sus principios y proyecto educativo, nacen y se enriquecen en la necesidad objetiva de buscar fórmulas de solución a los problemas concretos de cada país y circunstancia histórica, en la concreción de voluntades para hallar las soluciones más progresivas a las contradicciones dialécticas del desarrollo nacional.

El compromiso social, político, económico y cultural del modelo educativo de Martí, surge de la crítica a los modelos tradicionales de la educación con características clásicas y academicistas. La renovación de la educación en todos sus niveles y modalidades del proceso educativo, está marcada por el espíritu liberal de la época y el impulso del desarrollo económico, así como el compromiso por la justicia social y la independencia o soberanía de los países.

\section{Referencias bibliográficas}

Almendros, H. Ideario Pedagógico, La Habana: Editorial Pueblo y Educación, 1997. 
Dewey, J. Democracia y educación. Madrid: Ediciones Morata, 1998.

Gimeno, J. \& Pérez, A. Comprender y transformar la enseñanza. Madrid: Ediciones Morata, 2000.

Gimeno, J. Educar y convivir en la cultura global. Las exigencias de la ciudadanía. Madrid: Ediciones Morata, 2001.
Martí, José. Obras Completas. La Habana: Editorial de Ciencias Sociales de la Habana, 1975.

Pérez, F. El proyecto educativo martiano: principios para la praxis en el siglo XXI. Ponencia presentada en el 158 Aniversario del Nacimiento de Martí, Casa de las Américas, 31 de enero de 2003

Jacqueline García Fallas Docente de la Escuela de Filosofía y de la Escuela de Formación Docente de la Universidad de Costa Rica 